\title{
Prevalence and Factors Associated With Stunting Among Children Aged 6-59 Months in Kabale District, Uganda
}

Musa Kasajja ( $\sim$ musakasajja@yahoo.com )

Makerere University School of Public Health

Elizabeth Nabiwemba

Makerere University School of Public Health

Henry Wamani

Makerere University School of Public Health

Saul Kamukama

Makerere University School of Public Health

Research Article

Keywords: Stunting, Malnutrition and Under-nutrition

Posted Date: May 27th, 2021

DOI: https://doi.org/10.21203/rs.3.rs-528834/v1

License: (c) (i) This work is licensed under a Creative Commons Attribution 4.0 International License.

Read Full License 


\section{Abstract}

Background: Despite of the global efforts undertaken to improve nutrition, malnutrition still continues to be a serious public health concern. Malnutrition in its various forms has been closely associated to major causes of illness, disability and death. Malnutrition in the form of childhood stunting has therefore been identified as a significant hindrance to human development. The aim of this study was to assess the nutritional status of children aged 6-59 months and determine factors associated with stunting among children in Kabale district.

Methodology: A cross sectional study was conducted among 640 children, aged 6-59 months selected using both simple random and systematic random sampling techniques. Interview administered questionnaires were used to collect household data whereas anthropometric data was collected using a height board, digital weighing scales and Mid Upper Arm Circumference (MUAC) Tapes. Data was analyzed using STATA version 12.0 and ENA for SMART, 2011.

Results: The overall prevalence of stunting among children 6-59 months was $41.1 \%$. Factors independently associated with stunting included; age of the child (children in the age category of 3647 months APOR $=0.38 ; 95 \% \mathrm{Cl} 0.18-0.79$ and those in the age category of $24-35$ months APOR $=0.42 ; 95 \%$ $\mathrm{Cl}$ 0.19-0.88), major source of food for the household that is children from households in which mothers indicated market as the major source of food (APOR $=0.67 ; 95 \% \mathrm{Cl} 0.48-0.94)$ and disposal of child stool that is children whose stool was put/ rinsed in a latrine (APOR $=0.41 ; 95 \% \mathrm{Cl}: 0.23-0.74$ ) as well as those that whose stool was thrown in garbage (APOR=0.29; $95 \% \mathrm{Cl}$ : 0.12-0.72).

Conclusion: The prevalence of stunting among children aged 6-59 months in Kabale district was high. Practices/ factors independently associated with stunting among children aged 6-59months included; age of the child, major source of food for the household and disposal of child stool. Addressing these factors requires a proper mix of both community and health based interventions. There is also need to strengthen on strategies for reducing stunting like; sanitation and hygiene as well as food and nutrition security within rural households.

\section{Background}

Despite of the global efforts undertaken to improve nutrition, malnutrition still continues to be a serious public health concern(1). Malnutrition in its various forms such as; stunting, wasting, underweight and overweight has been closely associated to major causes of illness, disability and death(2) thus impeding economic advancement in most developing countries. Malnutrition in the form of childhood stunting has therefore been identified as a significant hindrance to human development(3).

Stunting has generally been described as low height-for-age (HAZ), that is a child having less than minus two standard deviations of the new World Health Organization (WHO) growth Standards(4). Stunting reflects a process of failure to reach linear growth potential as a result of suboptimal health and/ or nutrition conditions. Stunting is now a well-established risk marker of poor child development, especially 
in Sub-Saharan Africa. According to WHO, the worldwide variation of the prevalence of stunting is considered to range from 5 to $65 \%$ among less-developed countries. In developing countries, the prevalence of stunting starts to rise at about three months of age and then slows down at around three years of age(5). It has been noted that $90 \%$ of the world's stunted children live in 36 developing countries(6) of which Sub-Saharan Africa and South Asia are home to three quarters of the world's stunted children(7). Despite an encouraging global downward trend in the prevalence of stunting, the progress is not the same across countries(8) especially in Sub-Saharan Africa and South Asia.

Stunting is therefore thought to result from both the nutritional experience of the individual (child) over a period of time as well as the nutritional status of the parents, particularly the mother through birth weight(9). For instance it has been highlighted that intrauterine growth restriction due to maternal undernutrition estimated by rates of low birth weight accounts for $20 \%$ of childhood stunting(10). Stunting and other forms of under-nutrition reduce a child's chance of survival, while also hindering optimal health and growth. Stunting before the age of two years predicts poorer cognitive and educational outcomes in later childhood and adolescence(11) of which these have significant educational and economic consequences at the individual, household and community levels.

In Uganda, findings show that the nutritional status of the population is generally poor especially among children less than five years, children of school going age, adolescents and women of reproductive age(12). Data from the 2011 Uganda Demographic and Health Survey (UDHS) reports levels of child and maternal under-nutrition which have not changed much over the past 15 years. For instance $33 \%$ of children less than five years in Uganda are stunted which means that over and above 2.3 million young children are chronically malnourished, $14 \%$ are underweight and $5 \%$ are wasted. While there has been some reduction in the prevalence of child malnutrition, the change has been slow.

This study therefore assessed the prevalence and factors associated with stunting among children aged 6-59 months in Kabale district thus understanding why stunting was high in that part of Uganda.

\section{Methodology}

Study site, design and sample size: The study was carried out in Kabale district. The district has a population of 490,227 of which children under five years are 90,692(13). Two sub-counties (Ikumba and Hamurwa) out of 16 were studied reasons being that these sub-counties posted the highest number of malnourished children as per the district findings from a survey that was conducted in all sub-counties in November, 2014(14). The study employed a cross-sectional study design and quantitative methods of data collection were used. A sample of 640 children aged 6-59 months was selected using simple random and systematic sampling procedures. The inclusion criteria included all children aged 6-59 months with their biological mothers aged 15-49 years who had lived in the study area for a period of more than five years, and consented to participate in the study as proxy respondents. Mothers with very sick children and women who were living with children that didn't belong to them were excluded. 
Sampling Procedure: The study used both simple random and systematic sampling. Lists of all the villages in the two sub-counties that is Ikumba (59 villages) and Hamurwa (64 villages) were generated with the help of the District Biostatistician. From a combined total of 123 villages in the two sub-counties, 32 villages were randomly selected- that is 14 villages in Ikumba and 18 villages in Hamurwa. Within each village, 20 households were selected using systematic random sampling. The first household was arrived at using the Lot Quality Technique. Subsequent households were then selected using a sampling interval of three where two households had to be skipped after the first visited household. In circumstances where the visited household did not have eligible participants we had to go to the immediate household whose front door was physically closest to the one just visited. In households that had more than one child aged 6-59 months, children were assigned numbers out of which one was randomly selected to participate in the study.

Data collection procedure and tools: While in the community, research assistants conducted interviews using the local language (Rukiga) after obtaining written informed consent from respondents. Child's age was obtained from birth certificates. In cases where the birth certificates were missing, age was determined through probing and using the age in months calendar. Anthropometric measurements for weight, height and MUAC were taken using Seca digital weighing scales (Model 874), Shorry height boards, and adult MUAC tapes respectively. Weighing scales were tested for consistency every morning using a $2 \mathrm{~kg}$ stone, calibrated to zero and put on a flat surface for accurate measurements. Respondents were then asked to stand on the weighing scale without shoes and feet a little wide apart. Tethered weight was taken for children who could not stand and readings rounded off to the nearest $0.1 \mathrm{~kg}$. The height board was placed either vertically or horizontally on a flat surface. Length was taken for children below 24 months in a recumbent position of which height was taken for adults and children above 24 months, respondents were asked to stand straight on a vertically placed height board while facing the individual taking the height reading. The obtained readings were rounded off to the nearest $0.1 \mathrm{~cm}$. Adult MUAC readings were obtained from the mothers of which the mid-point of the arm had to first be obtained. The less active arm for each respondent had to be determined, then a reading of the upper arm's length in centimeters from the shoulder bone to the elbow joint was determined while the arm was folded at 90 degrees. The obtained reading was then divided into two equal parts to get the mid-point, it is at that part of the upper arm that a flexible tape designed to take adult MUAC was passed around a dropped arm and the reading determined.

MUAC measurements were also recorded to the nearest $0.1 \mathrm{~cm}$. Other variables such as sociodemographic factors and child feeding practices were obtained using an interview administered semistructured questionnaire. On average one interview lasted for 30 minutes.

Data management and statistical analysis: Raw data was cross-checked for completeness, cleaned and entered into a computer using EpiData 3.1. Statistical analysis was done using STATA version 12.0 software. Nutrition status data was analyzed using ENA for Smart version 2011, then categorized and exported to STATA for further analysis. Data analysis involved running frequencies and statistical associations. Prevalence odd ratios (POR) were used to test for associations. Factors with a P value $\leq$ 
0.2 at bivariate analysis, and those that were biologically plausible were subjected to the backward and forward stepwise method at multivariate analysis to determine factors independently associated with stunting. Factors with a P value of $<0.05$ were considered as statistically significant.

Ethicalconsiderations: Ethical approval for the study was obtained from Makerere University School of Public Health Higher Degrees Research and Ethics Committee as well as the Uganda National Council of Science and Technology. While in Kabale district, permission was obtained from the District Health Officer (DHO), Sub-county Chiefs and Local Council Chairpersons. Detailed information on study procedures and purpose were explained to mothers. Informed written consent was obtained from each mother before they participated in the study. Children who were found to be malnourished (wasted and underweight) were referred to the nearest health center of which mothers were encouraged to take their children for treatment. The study used numbers for identification of participants and the responses of the mothers were kept confidential.

\section{Results}

A total of 640 children participated in this study, the ratio of male to female children was $1: 1$. The mean age of children was 26.4 months with a standard deviation (SD) of + / - 14.05 and median age of 23.47 months. Most of the children who participated were residing in Hamurwa sub-county $56.2 \%$ (360), the rest were from Ikumba $43.7 \%$ (280). Baseline and socio demographic characteristics of the study population are presented in Table 1 below.

Prevalence of stunting (HAZ <-2 z-score) among children was $41.1 \%$. Males had a slightly higher prevalence of stunting $42.2 \%$ compared to females $40.0 \%$. Prevalence of underweight (WAZ <-2 z-score) among children was $7.7 \%$. Underweight was highest among females $9.3 \%$ compared to males $6.0 \%$. Prevalence of wasting ( $\mathrm{WHZ}<-2 \mathrm{z}$-score) was $1.3 \%$ in the study population. Wasting was highest among males $9 \%$ compared to females $0.6 \%$.

\section{Factors associated with stunting}

Factors/ practices independently associated with stunting among children aged 6-59 months were; age of the child (children in the age category of 36-47 months; APOR $=0.38$ and those in the age category of 24-35 months; APOR= 0.42), major source of food for the household that is children from households in which mothers indicated market as the major source of food $(A P O R=0.67)$ and disposal of child stool that is children whose stool was put and or rinsed in a latrine (APOR= 0.41$)$ as well as those that whose stool was thrown in garbage (APOR= 0.29). The results are presented in Table 2 below.

\section{Discussion}

This study is reflective of a predominantly rural population in southwestern Uganda. The study provides important insights about stunting and factors/ practices associated with stunting among children aged 6-59 months. Prevalence of stunting in the study population varied according to the different age groups 
and decreased with an increase in age, overall prevalence was $41.1 \%$. This prevalence was almost the same as the entire regional average of $41.7 \%$ reported in the 2011 UDHS, high compared to findings from previous studies in Uganda(13-15) and low compared to other countries in Sub-Saharan Africa and South Asia of which these include; Malawi, Ethiopia, DR Congo, Tanzania, Nigeria, India, Pakistan, Bangladesh and $\operatorname{Nepal}(7,16-19)$. Stunting has been associated with long-term consequences such as low education attainment, increased risk of non-communicable diseases, reduced work productivity and other socioeconomic disadvantages(11). The 2013 lancet series highlight that undernutrition is estimated to reduce a nation's economic advance by at least eight percent through direct productivity losses, losses via poor cognition and losses via reduced schooling(20) (21).

The factors that were significantly associated with stunting included; child's age, major source of food for the household and disposal of child stool. Findings revealed that the prevalence of stunting was slightly higher among male children (42.2\%) although this was not statistically significant. It has been noted that in Sub-Saharan Africa, male children are more likely to become stunted than females of which this may be attributed to vulnerabilities in health inequalities(22).

Findings also revealed that children in the age categories of 36-47 and 24-35 months were more likely to be affected by stunting compared to children in other age groups. This is consistent with a study that was carried out in Southern Ethiopia where children more likely to be stunted included those between 2435 months(23). In another study carried out in Acholi sub-region, the prevalence of stunting among children aged 6-59 months peaked at 30-41 months(15). However, in other studies, children more likely to be stunted were in the age categories of $11-23$ and $12-23(24,25)$. It should be noted that low height-forage in children aged 24-35 months reflects a continuing process of failing to grow (stunting) whereas for older children above 36 months, low height-for-age reflects a state of having failed to grow (being stunted).

Major source of food for the household was used as a proxy for household food security. Children in households that bought their food from the market were more likely to be stunted compared to those in households that grew their own food. This indicates that households which bought food from the village markets and or nearby shops as their major source of food did not have enough food to feed their children on. A study done in Malaysia showed that children in food-insecure households were three times more likely to be stunted than children in food-secure households(26). Another study carried out in Colombia showed that the risk for child stunting increased in a dose-response way as food insecurity became more severe(27). This finding was expected because the study was done before the harvest season.

Children whose stool was put/ rinsed in a latrine and those whose stool was thrown in garbage were more likely to be affected by stunting compared to those that used a latrine. It has been noted that access to improved sanitation and proper disposal of child's stool have conflicting associations with stunting, especially among the older group of children. On one hand, children from households with improved sanitation are less likely to be stunted. On the other hand, children from households where their stool is 
properly contained and or rinsed in a latrine are more likely to be stunted even after controlling for other variables, including sanitation(28). This finding implies that mothers' hygiene practices (like not washing their hands after disposing off child stool) have an effect on child health ultimately leading to stunting.

This study had a number of limitations. We did not consider seasonal variations and their effect on a range of factors affecting stunting among children in different households, though the study was conducted during a rainy season before harvest time. There might have been potential recall bias among respondents answering questions relating to events that happened in the past, especially to do with infant and young child feeding (IYCF) practices. However, questions to do with IYCF were asked based on a 24 hour recall so as to minimize the effect of recall bias. Information on some potential factors or confounding variables such as parasitic infestation which is wide spread among children was not assessed reason being that this required a longer period of time and a lot of resources. This being a cross-sectional study, causality could not be established for any of the associated variables.

\section{Conclusion}

The overall prevalence of stunting among children aged 6-59 months in Kabale district was high (41.1\%). However, there was a decrease in the prevalence by 7 percentage points compared to what was reported in 2014 (48\%). Practices/ factors independently associated with stunting among children aged 6-59 months were; age of the child, major source of food for the household and disposal of child stool. The risk of stunting increased with age hence the highest risk of stunting being among children aged 36-47 months. Children in households that bought food from the market and or nearby shops were more likely to be stunted. The findings also revealed that unhygienic child stool disposal (throwing of stool in garbage) was positively associated with stunting. Addressing these factors requires a proper mix of both community and health based interventions. There is also need to strengthen on strategies for reducing stunting like; sanitation, and hygiene as well as food and nutrition security within rural households.

\section{Abbreviations}

APOR: Adjusted Prevalence Odds Ratios

Cl: Confidence Intervals

DHO: District Health Officer

HAZ: Height for Age Z score

IYCF: Infant and Young Child Feeding

MUAC: Mid Upper Arm Circumference

POR: Prevalence Odds Ratios 
UDHS: Uganda Demographic and Health Survey

WAZ: Weight for Age Z score

WHO: World Health Organization

WHZ: Weight for Height Z scores

\section{Declarations}

Ethics Approval and Consent to Participate: Institutional guidelines were followed by acquiring ethical approval from Makerere University School of Public Health Higher Degrees Research and Ethics Committee as well as from the Uganda National Council of Science and Technology. This was followed by obtaining permission to conduct the study at the district, sub-county and village levels. While in the field, consent to participate in the study was sought from all study respondents.

Consent for Publication: Consent to use the obtained data for publication was sought from all respondents that participated in the study.

Availability of Data and Materials: The datasets used and/ or analyzed during the current study are available from the corresponding author on reasonable request.

Competing interest: The authors declare that they have no competing interests.

Funding: The study was privately funded.

Authors' Contributions: $\mathrm{MK}^{1}$ formulated, conceptualized and coordinated the study including supervision of data collection and data analysis. $\mathrm{EN}^{2}, \mathrm{HW}^{2} \& \mathrm{SK}^{2}$ contributed to the design of the study. All authors contributed to the interpretation of data and preparation of the manuscript.

Acknowledgement: To all respondents who participated in the study plus the cooperation of the District Health Officer and Local leaders.

\section{References}

1. USAID: Multi-Sectoral Nutrition strategy 2014-2025. http://www.usaid.gov/sites/default/files/documents/1867/USAID_Nutrition_Strategy_5-09_508.pdf; 2014.

2. WHO: Essential Nutrition Actions; Improving maternal , newborn, infant and young child health and nutrition; 2013. 
3. WHO: Global Nutrition Target 2025; Stunting Policy Brief.

http://www.who.int/nutrition/topics/globaltargets_stunting_policybrief.pdf; 2014

4. Badham J and Sweet L. Stunting: An Overview. Sight \& Life Magazine; 2010:40-7.

5. WHO: Global Database on Child Growth and Malnutrition, 2015 [cited: 9 March, 2015]. Available from: http://www.who.int/nutgrowthdb/about/introduction/en/index2.html.

6. Bhutta ZA, Ahmed T, Black RE, Cousens S, Dewey K, Giugliani E, Haider BA, Kirkwood B, Morris SS, Sachdev HPS, et al: What works Interventions for maternal and child undernutrition and survival. The Lancet. 2008; 371(9610): 417-40.

7. UNICEF: Improving Child Nutrition; The achievable imperative for global progress; 2013.

8. Muller O, and Krawinkel M: Malnutrition and health in developing countries. CMAJ 2005; 173(3): (279-286).

9. Medhin et al.: Prevalence and predictors of undernutrition among infants aged six and twelve months in Butajira, Ethiopia:The P-MaMiE Birth Cohort. BMC Public Health 2010 10:27.

10. Black RE VC, Walker SP, Bhutta ZA, Christian P, de Onis M, et al: Maternal and child undernutrition and overweight in low-income and middle-income countries. Lancet. 2013; 371:243-60. (doi:10.1016/S0140-6736(13)60937-X).

11. Walker SP, Chang SM, Powell CA, Simonoff E, Grantham-McGregor SM. Early childhood stunting is associated with poor psychological functioning in late adolescence and effects are reduced by psychosocial stimulation. J Nutr. 2007;137:2464-9.

12. Uganda Health sector strategic plan III 2010/2011- 2014/2015. Ministry of Health; 2010.

13. UBOS: Uganda Demographic and Health Survey 2011;2012.

14. Wamani H: Food Security and Nutrition Assessment in Ibanda, Kabale, Kanungu and Pader Districts; 2014. www.unr.ug

15. Wamani H: Report on Nutrition and Food Security Assessment in Acholi Sub-region; 2012. www.unr.ug

16. Mekides WT, Belachew ET \& Semaw FA: Under Nutrition and Associated Factors Among Under-Five Age Children of Kunama Ethnic Groups in Tahtay Adiyabo Woreda, Tigray Regional State, Ethiopia: Community based study. International Journal of Nutrition and Food Sciences. 2015; Vol. 4, No. 3, 2015, pp. 278-289. doi: 10.11648/j.ijnfs.20150403.15.

17. Alemu A, Sileshi G, Habtamu FG, Wondu G: Prevalence of Stunting and Associated Factors of Children among 6-59 Months Age in Guto Gida District, East Wollega Zone, Oromia, Ethiopia. Food Science and Quality Management, 2014;Vol.29, 2014. ISSN 2224-6088 (Paper) ISSN 2225-0557 (Online).

18. Mananga MJ, Kana-Sop MM, Nolla NP, Tetanye-Ekoe, Gouado I: Feeding Practices, Food and Nutrition Insecurity of infants and their Mothers in Bangang Rural Community, Cameroon. J Nutr Food Sci. 2014; 4: 264. doi: 10.4172/2155-9600.1000264. 
19. Fenske N, Burns J, Hothorn T, Rehfuess EA: Understanding Child Stunting in India: A Comprehensive Analysis of Socio-Economic, Nutritional and Environmental Determinants Using Additive Quantile Regression. PLoS ONE 8(11) 2013: e78692 doi:101371/journalpone0078692.

20. Horton S, \& Steckel, R. H: Global economic losses attributable to malnutrition 1990-2000 and projections to 2050. In: Lombard, B. How much have global problems cost the world? A scorecard from 1900 to 2050. [press release]: Cambridge University Press, 2013.

21. The Lancet, 2013: Maternal and child nutrition. http://andeguat.org.gt/wpcontent/uploads/2014/07/publication-completa-Lancet-MI.pdf.

22. Wamani, H, Åstrøm AN, Peterson S et al: Boys are more stunted than girls in Sub-Saharan Africa: A meta-analysis of 16 demographic and health surveys. BMC Pediatrics 2007, 7:17 doi:101186/14712431-7-17.

23. Moges B, Feleke A, Meseret S, Doyore F: Magnitude of Stunting and Associated Factors Among 6-59 Months Old Children in Hossana Town, Southern Ethiopia. J Clinic Res Bioeth 6: 207 (2015) doi:104172/2155-96271000207

24. Yalew BM, Amsalu F, Bikes D: Prevalence and Factors Associated with Stunting, Underweight and Wasting: A Community Based Cross Sectional Study among Children Age 6-59 Months at Lalibela Town, Northern Ethiopia. J Nutr Disorders Ther 4:147 (2014) doi:104172/2161-05091000147.

25. Ramos CV, Dumith SC, César JA: Prevalence and factors associated with stunting and excess weight in childrenaged 0-5 years from the Brazilian semi-arid region. J Pediatr (Rio J) 2015;91:175--82.

26. Naser IA, Jalil R, Wan Muda WM et al: Association between household food insecurity and nutritional outcomes among children in Northeastern of Peninsular Malaysia. Nutrition Research and Practice 2014; 8(3):304-31

27. Hackett M, Melgar-Quiñonez H, Álvarez MC: Household food insecurity associated with stunting and underweight among preschool children in Antioquia, Colombia. Rev Panam Salud Publica 2009; 25 (6):506-10.

28. Mbuya MN, Chidem M, Chasekwa B \& Mishra V: Biological, Social, and Environmental Determinants of Low Birth Weight and Stunting among Infants and Young Children in Zimbabwe, 2010. Accessed from: www.dhsprogram.com/pubs/pdf/WPZ7/WPZ7.pdf.

\section{Tables}

\section{Table 1: Baseline characteristics of the study population}




\begin{tabular}{|c|c|c|}
\hline Variable & Number $(n=640)$ & Percentage (\%) \\
\hline \multicolumn{3}{|l|}{ CHILD CHARACTERISTICS } \\
\hline \multicolumn{3}{|l|}{ Sex of the child } \\
\hline Male & 316 & 49.38 \\
\hline Female & 324 & 50.63 \\
\hline \multicolumn{3}{|l|}{ Age in months } \\
\hline $6-11$ & 106 & 16.56 \\
\hline $12-23$ & 224 & 35.00 \\
\hline $24-35$ & 151 & 23.59 \\
\hline $36-47$ & 93 & 14.53 \\
\hline $48-59$ & 66 & 10.31 \\
\hline \multicolumn{3}{|l|}{ Child's birth order } \\
\hline 1 & 127 & 19.84 \\
\hline $2-3$ & 217 & 33.91 \\
\hline $4-5$ & 163 & 25.47 \\
\hline$>5$ & 133 & 20.78 \\
\hline \multicolumn{3}{|l|}{ Nutrition status of Children } \\
\hline Stunting (HAZ < -2 Z-score) & 263 & 41.1 \\
\hline Underweight (WAZ $<-2$ Z-score) & 49 & 7.7 \\
\hline Wasting (WHZ <-2 Z-score) & 8 & 1.3 \\
\hline \multicolumn{3}{|c|}{ RESPONDENTS CHARACTERISTICS } \\
\hline \multicolumn{3}{|l|}{ Sex of the household head } \\
\hline Male & 607 & 94.84 \\
\hline Female & 33 & 5.16 \\
\hline \multicolumn{3}{|l|}{ Mothers' age in years } \\
\hline $15-19$ & 25 & 3.91 \\
\hline $20-24$ & 165 & 25.78 \\
\hline
\end{tabular}




\begin{tabular}{|c|c|c|}
\hline $25-29$ & 188 & 29.38 \\
\hline $30-34$ & 117 & 18.28 \\
\hline$\geq 35$ & 145 & 22.66 \\
\hline \multicolumn{3}{|c|}{ Marital Status of the Mother } \\
\hline Single & 11 & 1.72 \\
\hline Married & 428 & 66.88 \\
\hline Cohabiting & 173 & 27.03 \\
\hline Widowed & 12 & 1.88 \\
\hline Divorced/ Separated & 16 & 2.50 \\
\hline \multicolumn{3}{|c|}{ Mothers' education level } \\
\hline None & 70 & 10.94 \\
\hline Primary & 494 & 77.19 \\
\hline Secondary & 70 & 10.94 \\
\hline Some tertiary & 6 & 0.94 \\
\hline \multicolumn{3}{|l|}{ Mothers' Occupation } \\
\hline Farmer & 622 & 97.19 \\
\hline Petty trade & 18 & 2.81 \\
\hline \multicolumn{3}{|c|}{ Major source of food for the household } \\
\hline Own production & 371 & 57.97 \\
\hline Market & 269 & 42.97 \\
\hline \multicolumn{3}{|l|}{ Household size } \\
\hline $2-4$ & 254 & 36.69 \\
\hline $5-7$ & 275 & 42.97 \\
\hline$>8$ & 111 & 17.34 \\
\hline \multicolumn{3}{|c|}{ Area of residence (Sub-county) } \\
\hline Ikumba & 280 & 43.75 \\
\hline Hamurwa & 360 & 56.25 \\
\hline
\end{tabular}


Table 2: Overall factors associated with stunting among children aged 6-59 months 
Variable

Female

Male

Age of the child

48-59

36-47

$12-23$

139 (37.5) 232 (62.5)

124 (46.1) 145 (53.9)

85 (80.2)

Bi-variable

Analysis

Crude POR

$(95 \% \mathrm{Cl})$
Multivariable

Analysis

Adjusted POR

(95\% Cl)

$\begin{array}{lll}130(40.0) & 195(60.0) & 1.00 \\ 133(42.2) & 182(57.8) & \begin{array}{l}0.91(0.66- \\ 1.23)\end{array}\end{array}$

0.83 (0.59-

1.16)

\begin{tabular}{|c|c|c|c|}
\hline $15(22.7)$ & 51 (77.3) & 1.00 & \\
\hline $44(47.3)$ & $49(52.7)$ & $\begin{array}{l}0.33(0.16- \\
0.66)\end{array}$ & $\begin{array}{l}0.38(0.18- \\
0.79)\end{array}$ \\
\hline
\end{tabular}

24-35

6-11

Major source of food for household

Own production

Market

\section{Person feeding the index child}

Mother

Father

Elder sibling

Child eats by him/ herself

\begin{tabular}{ll}
$79(52.3)$ & 72 \\
$\begin{array}{l}104(46.4) \\
(56.6)\end{array}$ & 120 \\
\hline
\end{tabular}

21 (19.8)

$\begin{array}{ll}0.27(0.14- & 0.42(0.19- \\ 0.52) & 0.88)\end{array}$

$\begin{array}{ll}0.34(0.18- & 0.56(0.26- \\ 0.64) & 1.17)\end{array}$

$1.19(0.56-$

2.52)

$1.83(0.74-$

4.52)
$0.38(0.18-$

$0.42(0.19-$

$0.56(0.26-$ $1.17)$

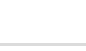




\begin{tabular}{|c|c|c|c|c|}
\hline & & & $\begin{array}{l}0.51(0.327- \\
0.805)\end{array}$ & $\begin{array}{l}0.41(0.23- \\
0.74)\end{array}$ \\
\hline Buried & $40(40.8)$ & $58(59.2)$ & $\begin{array}{l}0.58(0.326- \\
1.019)\end{array}$ & $\begin{array}{l}1.59(0.32- \\
1.13)\end{array}$ \\
\hline Thrown in garbage & $18(56.2)$ & $14(43.8)$ & $\begin{array}{l}0.31(0.138- \\
0.693)\end{array}$ & $\begin{array}{l}0.29(0.12- \\
0.72)\end{array}$ \\
\hline
\end{tabular}

POR $(95 \% \mathrm{Cl})=$ Prevalence Odds Ratio and its $95 \%$ Confidence interval. P-values $\otimes 0.05$ are statistically significant. 